Çukurova Üniversitesi Mühendislik Mimarlık Fakültesi Dergisi, 32(4), ss. 147-152, Aralık 2017

Çukurova University Journal of the Faculty of Engineering and Architecture, 32(4), pp. 147-152, December 2017

\title{
Pamuk Yağı Biyodizelinin Motor Ses Seviyesine Olan Etkilerinin İncelenmesi
}

\author{
Ahmet ÇALIK ${ }^{* 1}$ \\ ${ }^{1}$ Adana Bilim ve Teknoloji Üniversitesi, Mühendislik Fakültesi, Makine Mühendisliği Bölümü, \\ Adana
}

$\ddot{O} \mathbf{z}$

Geliş tarihi: 23.11.2017～Kabul tarihi: 19.12.2017

Dizel motorlar, sağladıkları yakıt ekonomisi ve yüksek termal verimleriyle günümüzde en çok tercih edilen motor tipidir. Ancak sıkıştırma ateşlemeli motorlarda yüksek sıkıştırma oranından dolayı meydana gelen ses dizel motorların en önemli dezavantajlarındandır. Yakıtın yanması sırasında meydana gelen ses hem yolcuların hem de sürücünün yolculuk konforunu azalmasına yol açmaktadır. Biyodizel, bitkisel ve hayvansal yağlardan elde edilebilen dizel yakıta alternatif yenilenebilir enerji kaynağıdır ve mevcut dizel motorlarda değişiklik yapmadan kullanılabilir.

Bu çalışmada, pamuk yağı esterinin dizel motorlarda kullanımının motorlarda ses seviyesine olan etkileri deneysel olarak incelenmiştir. Yakıt olarak PB20 ve PB100 kullanıldığında test motoru tarafindan üretilen ses seviyelerinin $\mathrm{dB}(\mathrm{A}), \mathrm{dB}(\mathrm{C})$ ve $\mathrm{dB}(\mathrm{Z})$ cinsinden dizel yakıtla karşılaştırıldı̆̆ında azaldığı gözlemlenmiştir.

Anahtar Kelimeler: Biyodizel, Desibel, Pamuk yap metil esteri, Ses seviyesi

\section{Investigation of Effects of Cotton Oil Biodiesel on Engine Noise Level}

\begin{abstract}
Diesel engines are the most preferred engine type today with their fuel economy and high thermal efficiency. However, the noise coming from compression ignition engines due to the high compression ratio, is a major disadvantage of diesel engines. The noise created during combustion of the fuel leads to a decrease in the riding comfort of both the passenger and the driver. Biodiesel is an alternative renewable energy source for diesel fuel that can be obtained from vegetable and animal oils and can be used without modification in existing diesel engines.

In this study, the effect of the use of cottonseed ester on diesel engines in engines was investigated experimentally. It has been observed that when using PB20 and PB100 as fuel, the sound levels produced by the test motor are reduced when compared to diesel in $\mathrm{dB}(\mathrm{A}), \mathrm{dB}(\mathrm{C})$ and $\mathrm{dB}(\mathrm{Z})$.
\end{abstract}

Keywords: Biodiesel, Decibel, Cotton methyl ester, Sound level

*Sorumlu yazar (Corresponding author): Ahmet ÇALIK, acalik@adanabtu.edu.tr 


\section{GíRiş}

Dizel motorların taşımacılık sektöründe hatırı sayılır bir alan bulması, dizel motorların sebep olduğu egzoz emisyonları çevre kirliliğini önemli ölçüde artırmaktadır [1]. Dizel motorların yarattığg bu çevre kirliliği, çevre dostu biyodizel yakıtlara eğilimi hızla artırmaktadır.

Biyodizel, bitkisel yağlar, hayvansal yağlar ve geri dönüştürülmüş restoran gresinden elde edilen çevre dostu bir alternatif dizel yakıttır [2]. Biyodizel, düşük emisyon profili ile yenilenebilir, biyolojik olarak parçalanabilen bir biyoyakıt çeşididir [3].

Birçok insan sağlığı tehlikesinin dizel egzoz emisyonlarına maruz kalma ile ilişkili olduğu literatürde sıkça yer almaktadır [4]. Dahası, karayolu trafiğinin yarattığı gürültü insan sağlığını olumsuz yönde etkilemektedir. $\mathrm{Bu}$ nedenle dizel motorların gürültü düzeyini azaltmak için yapılan araştırmalar oldukça önem arz etmektedir [5].

Sesin hızı, dizel motorlarda, özellikle de basınç ile aktive edilen enjektörler için yakıt enjeksiyonunu ve NOx emisyonlarını doğrudan karakterize eden önemli bir yakıt termofizik özelliğidir [6]. Literatürde, biyodizel yakıtları kullanan motorların ses hızının deneysel olarak alınmasına çok az rastlanılmaktadır.

Nikolic ve arkadaşları (2012) [7] Konvansiyonel yakıt enjeksiyon sistemini (CFIE) analiz etmişlerdir. Çalışmada ses, yoğunluk gibi belirli yakıt özelliklerinin ve hacim modülü, yakıt enjeksiyon sistemlerinin çalışması üzerinde önemli bir etkiye sahip olduğunu rapor etmişlerdir.

Uludamar ve arkadaşları (2016) [8] çeşitli biyodizellerin motor gürültüsü ve titreşimi üzerindeki etkisini, modifiye edilmemiş bir sıkıştırma ateşlemeli motorda incelenmiştir.

Uludamar ve arkadaşları (2016) [9], motora ayçiçeği, kanola ve mısır biyodizel karışımlarıyla ortaya çıkan gürültü ve titreşim özelliklerini kavrayabilmek için modifiye edilmemiş, dört zamanlı dört silindirli sıkıştırmalı ateşleme motorunda deneysel bir araştırma yapılmıştır. Ayrıca çalışmalarında motor giriş havasına hidrojen enjekte edilerek motor üzerindeki etki incelenmiştir. Sonuçlar, hidrojen eklemesiyle birlikte ses seviyesinin değişmesinin motor hızına bağlı olduğunu, buna karşın titreşim ivmesinin tüm motor devirlerinde hidrojen ilavesiyle azaldı̆̆ını ortaya koydular.

Sanjid ve arkadaşları (2014) [5] tek silindirli bir dizel motorunda, palmiye ve jatropha harmanının özgül yakıt tüketimi, motor gücü, egzoz ve gürültü özelliklerini 1400 ila 2200 dev/dak arasında değişen farklı motor hızlarında değerlendirmek için deneysel çalışma yapmışlardır. PBJB5 ve PBJB10 biyodizellerinin dizel yakıttan biraz daha yüksek bir BSFC gösterdiği halde, ölçülen emisyon parametreleri ve gürültü emisyonlarının önemli ölçüde azaltıldığını rapor etmişlerdir.

Tat ve arkadaşları (2000) [10] yaptıkları çalışmada, soya yağı metil ve etil esterleri için ses ve izentropik hacimsel modülün ölçümlerinin sonuçlarını analiz etmiş̧lerdir. Soya yağı monoesterlerinin ses hızının ve hacimsel modülünün dizel yakıtı hızından daha yüksek olduğunu ve bunların dizel motorların yakıt enjeksiyon zamanlamasında değişikliğe neden olabileceğini tespit etmişlerdir.

Bu çalışmada, modiye edilmemiş bir dizel motorun ses seviyesi dizel ve biyodizel kullanırak incelenmiştir. İncelemelerde pamuk yağı metil esteri ham (P100) ve dizel ile hacimsel olarak \%20 oranında karıştırılarak (P20) deneyler gerçekleştirilmiştir. Ses seviyeleri A- ağırlıklı $(\mathrm{dB}(\mathrm{A})), \mathrm{C}$ - ağırlıklı $(\mathrm{dB}(\mathrm{C}))$ ve ağırlıksız $(\mathrm{dB}(\mathrm{Z}))$ olarak incelenmiştir.

\section{MATERYAL VE METOT}

Motor testlerinde kullanılan biyodizel yakıtları transesterifikasyon yöntemi ile dönüştürülmüştür. $\mathrm{Bu}$ yöntemde katalizör (sodyum hidroksit) reaktantın (metanol) içerisinde karıştırılarak çözünürken pamuk yağ $155^{\circ} \mathrm{C}$ dereceye 1 sitılmıştır. Yağ sabit sıcaklığa ulaştıktan sonra, çözelti üzerine eklenmiş ve bu sicaklıkta 1,5 saat 
transesterifikasyon işlemi gerçekleştirilmiştir. İşlemden sonra ham metil ester ayırma hunisine alınmış ve gliserinin çökmesi 8 saat boyunca beklenmiştir. Çöken gliserin ayrıldıktan sonra metil ester 4 defa belli oranda (metil ester hacminin yaklaşık \%25'i) 1lık su ilave edilerek yıkanmıştır. İçeride kalan suyun buharlaştırılması için kurutma işlemi $105{ }^{\circ} \mathrm{C}$ karıştırılırsak 2 saat boyunca gerçekleştirilmiş ve son olarak filtreleme operasyonu uygulanmıştır.

Testler sırasında 4 zamanlı, 4 silindirli bir dizel motor kullanılmıştır. Motor özellikleri Çizelge 1'de gösterilmiştir.

Çizelge 1. Deneyde kullanılan motor özellikleri

\begin{tabular}{|l|l|}
\hline Marka & Mitsubishi \\
\hline Model & 4D34-2A \\
\hline Ateşleme sırası & $1-3-4-2$ \\
\hline Silindir dizilimi & Sıralı \\
\hline Silindir sayısı & 4 \\
\hline Silindir hacmi & $3907 \mathrm{cc}$ \\
\hline Silindir çapı & $104 \mathrm{~mm}$ \\
\hline Silindir stroğu & $115 \mathrm{~mm}$ \\
\hline Maksimum güç & $89 \mathrm{~kW} @ 3200 \mathrm{rpm}$ \\
\hline Maksimum tork & $295 \mathrm{Nm} @ 1800 \mathrm{rpm}$ \\
\hline
\end{tabular}

Motorun ses ölçümü sırasında ses yansımasını önlemek için odanın içerisi ve dinamometrenin etrafı özel ses emici panellerle kaplanmıştır. Gerçekleştirilen testlerde Gras marka 46AF tipi mikrofon seti ve Sinus marka Soundbook MK-2 model akustik ve ses ölçüm sistemi kullanılmıştır. Deneylerde kullanılan mikrofonunu frekans aralığ $3,15 \mathrm{~Hz}$ ile $20 \mathrm{kHz}$ aralığında olup hassasiyeti $50 \mathrm{mV} / \mathrm{Pa}$ 'dır. Ses ölçümlerinde mikrofon motor bloğunun yan yüzeyine bakacak şekilde 1 metre uzakta yerleştirilmiştir. Deney sırasında test motoru yüksüz olarak 1200, 1500, 1800 ve $2100 \mathrm{dev} /$ dak hızında çalıştırılmış ve ses ölçümleri 12 sn boyunca alınmıştır.
Desibel özünde bir birim olmamakla beraber iki ses seviyesi arasında bir ilişkidir. Desibelin logaritmik bir ölçü olup bu şekilde kullanılmasının başlıca sebebi çok küçük ve çok büyük rakam kullanım karışıklığını gidermektedir. Ses seviyesinin 2'ye katlanması sadece 3 dB'lik bir fark yaratmakta, 10'a katlanması ses 10 desibel'lik bir fark yaratmaktadır. Bir noktadaki toplam ses basıncı formül (a)'da, Farklı kaynaklardan yayılan $\mathrm{N}$ adet toplam ses düzeyi ise formül b'de sunulmuştur.

$L_{p i}=10 \log \left(\frac{p_{i}}{p_{\text {ref }}}\right) \rightarrow\left(\frac{p_{i}}{p_{\text {ref }}}\right)^{2}=10^{\left(L_{p_{i}} 10\right)}$

$L_{p t}=10 \log \left(\left(\frac{p_{1}}{p_{r e f}}\right)^{2}+\left(\frac{p_{2}}{p_{r e f}}\right)+\ldots\right) L_{p t}=10 \log \left(\sum_{i=1}^{N} 10^{L_{p i} / 10}\right)$

A- ağırlıklı fitreleme insan kulağının sese verdiği tepkiler göz önüne alınarak filtrelenmektedir. Ölçüm, aralığı $20 \mathrm{~Hz}$ ile $20 \mathrm{kHz}$ arasında olacak biçimde filtrelenmekte ve insan kulağının düşük seviyedeki tepkileri algılayabileceği şekilde olmaktadır. C- ağırlıklı filtreleme ise insan kulağının yüksek seviyedeki gürültülere daha iyi tepki verecek bir şekle sahiptir. Z-ağırlıklı desibel ise frekans ağırlığı olmadan $10 \mathrm{~Hz}$ ve $20 \mathrm{kHz} \pm 1,5 \mathrm{~dB}$ frekans aralığında sunulmaktadır.

$\mathrm{Bu}$ çalışma kapsamında dizel ve biyodizel ile çalışan bir dizel motorun akustik incelemesi değişik filtreleme yöntemleri uygulanarak yapılmıştır. Deneylerde A-ağırlıklı desibel dB[A], C- ağırlıklı desibel $\mathrm{dB}[\mathrm{C}]$ ve ağırlıksız olarak desibel cinsinden ölçümler alınmıştır.

\section{BULGULAR VE TARTIŞMA}

Dizel ve biyodizele ait bazı yakıt özellikleri Çizelge 2'de sunulmuştur. Yanma kalitesini gösterici nitelik taşıyan setanın pamuk biyodizelinde daha düşük olduğu belirlenmiştir. Biyodizelin en büyük dezavantajlarından biri olan kinematik vizkositenin yüksekliğinin ise pamuk biyodizeli için de geçerli olduğu yapılan ölçümler sonucu görülmüştür. 
Cizelge 2. Dizel ve biyodizel yakıt özellikleri

\begin{tabular}{|l|c|c|}
\hline & Dizel & P100 \\
\hline Yoğunluk $\left(\mathrm{kg} / \mathrm{m}^{3}\right)$ & 834 & 886 \\
\hline Setan sayıs1 & 59,1 & 55,4 \\
\hline $40{ }^{\circ} \mathrm{C}$ 'de & 2,6 & 4,4 \\
Kinematik viskozite $\left(\mathrm{mm} / \mathrm{s}^{2}\right)$ & 70 & $>140$ \\
\hline Alevlenme noktas1 $\left({ }^{\circ} \mathrm{C}\right)$ & 44,2 & 38,9 \\
\hline Alt Isıl Değer $(\mathrm{MJ} / \mathrm{kg})$ &
\end{tabular}

Ses oldukça kompleks bir olgudur [9]. Bir taşıtta motorun sesinin incelenmesinin birçok yönden faydalı olduğu bilinmektedir. Bunların başında motorun arıza teşhisi ve aracın konforu yer almaktadır. İçten yanmalı bir motorda ses genellikle mekanik, yanma ve aerodinamik etkenlerden dolayı oluşmaktadır. Mekanik sesler pistonlardan, kayışlardan ve enjektör sisteminden yayılırken, yanma sesleri başlica olarak silindirdeki basınç değişikliğinden oluşmaktadır. Aerodinamik sesler ise başlıca olarak motor hava emişi ve egzoz sırasında ortaya çıkmaktadır [11]. Şekil 1, 2, 3 ve 4'te sirasiyla motor hizı 1200 , $1500,1800,2100$ ve 2400 iken $\mathrm{dB}(\mathrm{A}), \mathrm{dB}(\mathrm{C})$ ve $\mathrm{dB}(\mathrm{Z})$ olarak motordan kaynaklanan sesler ölçülmüştür.

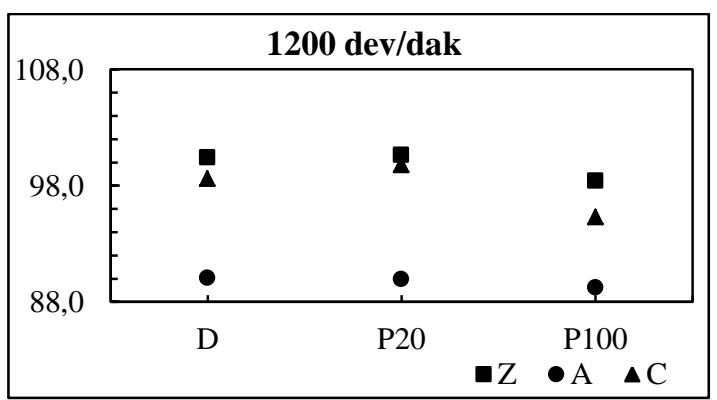

Şekil 2. $1200 \mathrm{dev} /$ dak'da yakıtların oluşturduğu gürültü

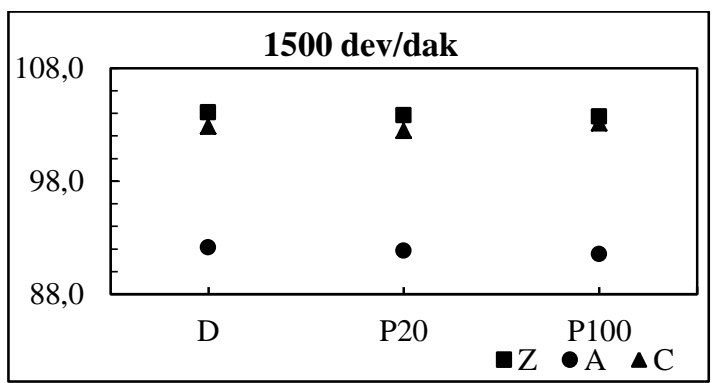

Şekil 3. 1500 dev/dak'da yakıtların oluşturduğu gürültü

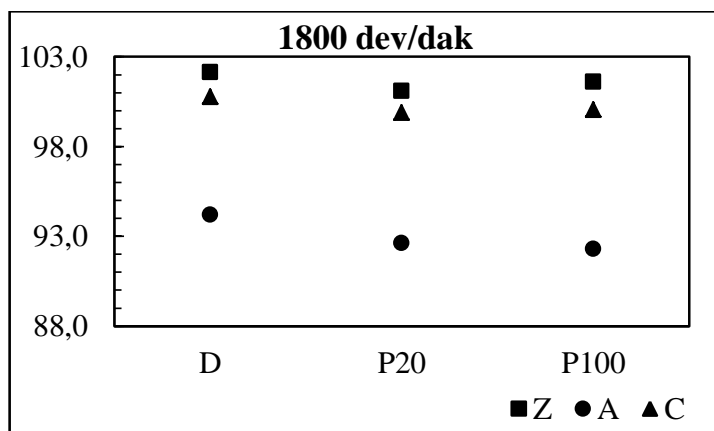

Şekil 4. $1800 \mathrm{dev} /$ dak'da yakıtların oluşturduğu gürültü

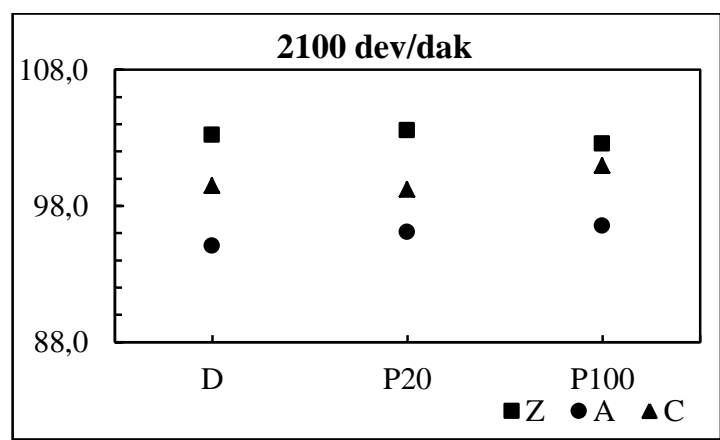

Şekil 5. $2100 \mathrm{dev} /$ dak'da yakıtların oluşturduğu gürültü

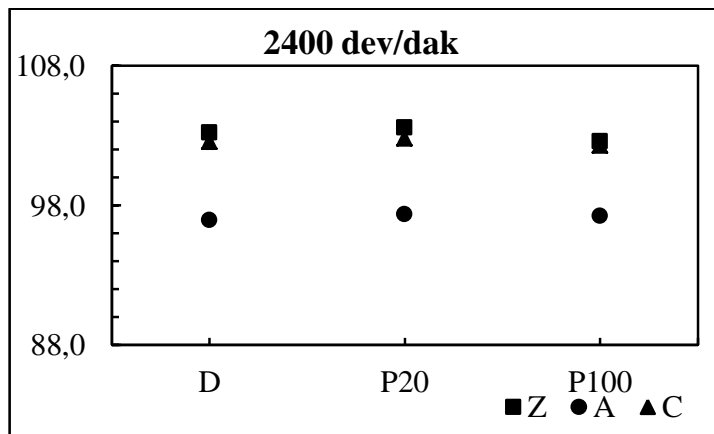

Şekil 6. $2400 \mathrm{dev} /$ dak'da yakıtların oluşturduğu gürültü

Yukarıdaki şekillere göre A-ağırlıklı olarak sesin motor hızıyla artış gösterdiği belirlenmiş̧tir. Ancak C- ve Z- ağırlığında 1500 dev/dak'ya kadar arttı̆̆ı, bu devirden sonra ise 2100 dev/dak hiza kadar azaldığı, $2400 \mathrm{dev} /$ dak'da ise tekrar artış gösterdiği tespit edilmiştir. Motor gürültü kaynaklarını oluşturan başlıca parametreler gaz akışı, yanma ve 
mekanik sesleridir. Bu yüzden motor bloğu titreşiminin motor hızıyla artması ses şiddetinin $\mathrm{dB}[\mathrm{A}]$ cinsinden sürekli artış göstermesi olarak yorumlanabilir. $\mathrm{dB}[\mathrm{C}]$ ve $\mathrm{dB}[\mathrm{Z}]$ cinsinden azalmanın olmasının muhtemel başlıca sebebi motor parçalarının bir kısmının 1200-1500 dev/dak hızında rezonansa bölgesine yakın olup yüksek ses şiddetleri oluşturması olarak yorumlanabilir.

Bütün filtrelerde biyodizel kullanımının motorun ses seviyesini azalttığı belirlenmiştir. Teste kullanılan Dizel yakıt ile karşılaştırıldığında P20 yakıtı ve P100 yakıt eklentisinin dB(A) cinsinden ses seviyesini 0,1 ve 0,$3 ; \mathrm{dB}(\mathrm{C})$ cinsinden 0 ve 0,$5 ; \mathrm{dB}(\mathrm{Z})$ cinsinden ise 0,2 ve 0,7 azaldığı hesaplanmıştır. Biyodizelin fazladan oksijen molekülü içermesi dizel yakıta göre daha kaliteli bir yanma gerçekleştirebilmesini sağlamıştır. Daha kaliteli yanma ile tutuşma gecikmesi azalmış, bu sayede artık gazların geç yanması yani kumandalı yanma ve art yanma düşmüştür. Motorun daha az titremesi ise ortama daha düşük seviyede ses yayması olarak yorumlanabilir.

\section{SONUÇLAR}

$\mathrm{Bu}$ çalışmada dizel bir motorda dizel ve pamuk biyodizeliyle kullanıldığında oluşan ses seviyesi $\mathrm{dB}(\mathrm{A}), \mathrm{dB}(\mathrm{C})$ ve $\mathrm{dB}(\mathrm{Z})$ cinsinden belirlenmiş ve karşılaştırılmıştır. Çalışma sonucu elde edilen verilere göre;

- Pamuk biyodizelinin setan sayısının ve altı 1sıl değerinin dizel yakıta göre daha düşük olduğu,

- Alevlenme noktasının ve kinematik vizkositesinin daha yüksek olduğu,

- Ses seviyesinin $\mathrm{dB}(\mathrm{A})$ cinsinden devir arttıkça $\operatorname{artığı~}$

- $\mathrm{dB}(\mathrm{C})$ ve $\mathrm{dB}(\mathrm{Z})$ cinsine göre $1500 \mathrm{dev} /$ dak'dan sonra azaldığ

- Biyodizel kullanımının ses seviyesini bütün ağırlıklarda azaltmaya sebep olduğu

sonucuna varılmıştır.

\section{KAYNAKLAR}

1. Özgür, C. 2017. Palm Biyodizel-Dizel Yakıt Karışımlarının Yakıt Özelliklerinin Tahmini Prediction of Fuel Properties of Palm Biodiesel-Diesel Fuel Blends. Çukurova University Journal of the Faculty of Engineering and ArchitectureÜ. Müh. Mim. Fak. Dergisi, 32 (321), 81-88.

2. Tat, M.E., Gerpen, J.H. 2003. Effect of Temperature and Pressure on the Speed of Sound and Isentropic Bulk Modulus of Mixtures of Biodiesel and Diesel Fuel. Journal of the American Oil Chemists' Society, 80 (11), 1127-1130.

3. Liaquat, A.M., Masjuki, H.H., Kalam, M.A., Fattah, I.M.R., Hazrat, M.A., Varman, M., Mofijur, M., Shahabuddin, M. 2013. Effect of Coconut Biodiesel Blended Fuels on Engine Performance and Emission Characteristics. Procedia Engineering, 56, 583-590.

4. Kagawa, J. 2002. Health Effects of Diesel Exhaust Emissions--a Mixture of Air Pollutants of Worldwide Concern. Toxicology, 181-182, 349-353.

5. Sanjida, A., Masjuki, H.H., Kalam, M.A., Ashrafur Rahman, S.M., Abedin, M.J., Reza, M.I., Sajjad, H. 2014. Experimental Investigation of Palm-jatropha Combined Blend Properties, Performance, Exhaust Emission and Noise in an Unmodified Diesel Engine. Procedia Engineering, 90, 397-402.

6. Freitas, S.V.D., Paredes, M.L.L., Daridon, J.-L. Lima, Á.S., Coutinho, J.A.P. 2013. Measurement and Prediction of the Speed of Sound of Biodiesel Fuels. Fuel, 103 (2), 1018-1022.

7. Nikolić, B.D., Kegl, B., Marković, S.D., Mitrović, M.S. 2013. Determining the Speed of Sound, Density and Bulk Modulus of Rapeseed Oil, Biodiesel and Diesel Fuel. Thermal Science, 16 (SUPPL.2), 505-514.

8. Uludamar, E., Tosun, E., Aydın, K. 2016. Experimental and Regression Analysis of Noise and Vibration of a Compression Ignition Engine Fuelled with Various Biodiesels. Fuel, 177, 326-333.

9. Uludamar, E., Yildizhan, Ş., Aydin, K., Özcanli, M. 2016. Vibration, Noise and 
Exhaust Emissions Analyses of an Unmodified Compression Ignition Engine Fuelled with Low Sulphur Diesel and Biodiesel Blends with Hydrogen Addition. International Journal of Hydrogen Energy, 41 (26), 11481-11490.

10. Tat, M.E., Van Gerpen, J.H., Soylu, S., Canakci, M., Monyem, A., Wormley, S. 2000. The Speed of Sound and Isentropic Bulk Modulus of Biodiesel at $21^{\circ} \mathrm{C}$ from Atmospheric Pressure to $35 \mathrm{MPa}$. Journal of the American Oil Chemists' Society, 77 (3), 285-289.

11. Yao, J., Xiang, Y., Qian, S., Li, S., Wu, S. 2017. Noise Source Separation of Diesel Engine by Combining Binaural Sound Localization Method and Blind Source Separation Method. Mechanical Systems and Signal Processing, 96, 303-320.

12. Çelebi, K., Uludamar, E., Tosun, E., Yıldızhan, Ş., Aydın, K., Özcanlı, M. 2017. Experimental and Artificial Neural Network Approach of Noise and Vibration Characteristic of an Unmodified Diesel Engine Fuelled with Conventional Diesel and Biodiesel Blends with Natural Gas Addition. Fuel, 197, 159-173. 